\title{
Equations for Estimating Percentage of Body Fat in Children 10-14 Years Old
}

\author{
RALPH R. FRERICHS, DAVID W, HARSHA, AND GERALD S. BERENSON ${ }^{1321}$
}

Depariments of Public Healih and Preventive Medicine, and Medicine, Louisiana State University Medical School, New Orleans; and the Department of Anthropology, Tulane University, New Orleans, Lonisiana, USA

\begin{abstract}
Summary
Measurements of the percentage of body fat (derived by underwater weighing), height, weight, and triceps skinfold thickness were determined for a volunteer sample of 214 children, 10-14 years old. The bivariate correlations, by sex, of percentage of body fat with five obesity indices are highest with the triceps skinfold and least with weight-height. Five sets of equations are presented for predicting percentage of body fat based on measurements of either height and weight, triceps skinfold, or height, weight, and triceps skinfold. Cumulative frequency distributions of the percentage of body fat (based on height, weight, and triceps skinfold) are shown by race and sex for a total community of 10- to 14-year olds.
\end{abstract}

Obesity has been associated with numerous conditions in adults such as hypertension, diabetes mellitus, and coronary artery disease (16). The onset of obesity frequently occurs during childhood (I I), a time when the overweight child already exhibits elevated levels of blood pressure (25), insulin (5), and serum lipids and lipoproteins (10).

Although obesity has been defined as an excess ratio of fat to fat-free body mass (6), in children no general agreement exists concerning either how to measure body fat or what level is excessive $(16,26)$. The most common indirect method for determining whether a child is obese is visual assessment or, more quantitatively, the use of standardized height and weight tables. More valid methods for determining percentage of body fat such as cadaver analysis (27), densitometry (28), or whole body counting of radioisotopic potassium $40(7)$ are either not applicable or are too involved for most clinical or epidemiologic studies.

While conducting a pediatric community study in Bogalusa, Louisiana, of cardiovascular disease risk factor variables in children $(8,9,23,24)$, it became readily apparent that indirect approaches were necessary for estimating body fat applicable to large populations. Based on densitometric and anthropometric measurements derived from a volunteer sample of children of Bogalusa $(12,13)$, we developed a series of equations for predicting both density and percentage of body fat. In this paper, we present five sets of simple equations which predict percentage of body fat in children, 10-14 years old, based on measures of either height and weight, triceps skinfold thickness, or a combination of height, weight, and triceps skinfold thickness. As a reference standard, the percentage of body fat was estimated for a total population of black and white 10- to 14-year-olds.

\section{MATERIALS AND METHODS}

SAMPLE POPULATION

Two populations of children of Bogalusa, Louisiana, 10-14 years old, are included in this analysis. The first is a sample derived from a study of 242 volunteer children who participated in an anthropometric and densitometric study during the summers of 1975 and 1976 (13). Excluding those younger than 10 and older than 14 years, the population was reduced to 214 children, 127 (59\%) whites, 87 (41\%) blacks, and $111(52 \%)$ males.

The second population is derived from 3524 children, 5-14 years old, who were examined during the 1973-1974 school year as part of the Bogalusa Heart Study (93\% participation) $(8,9,23$, $24)$. Of these, 1939 were $10-14$ years old $(63 \%$ whites, $37 \%$ blacks, and $53 \%$ males) and are included in this presentation. Appropriate written permission was obtained from parent or guardian before the examinations.

\section{ANTHROPOMETRIC MEASUREMENTS}

Height, weight, and the right triceps skinfold thickness were measured on each child as previously described (8). All children were dressed in either hospital gowns or bathing suits depending on the study. Height was measured to the nearest $0.1 \mathrm{~cm}$ and weight to the nearest $0.1 \mathrm{~kg}$. Using the Lange caliper (Cambridge Scientific Industries, Cambridge, MA), the triceps skinfold thickness was measured three separate times, each to the nearest $1 \mathrm{~mm}$ with the mean of the three readings included in the analysis. In addition, five skinfolds (biceps, subscapular, suprailiac, subcostal, and calf) were measured on the volunteer sample of 214 children as described elsewhere (13). One of the authors (D.W.H) took all measurements on the volunteers in the body density study. The anthropometric determinations on the sample of 1939 were made by a team of 10 trained examiners who periodically underwent retraining in anthropometric methodology during the period of the study. Three of these examiners performed $96 \%$ of the measurements taken.

In this presentation, emphasis is placed on using the triceps rather than any of the other five skinfolds for estimating percentage of body fat. Consequently, a detailed explanation of the measurement technique is given. The site used is the midpoint (half the distance between the acromion and the olecranon) of the right upper arm over the triceps muscle. A cross is marked with a felt tip pen at the midpoint parallel and perpendicular to the longitudinal axis of the arm. The child stands with his partly closed right hand, palm up, placed into a loosely formed cup of his left hand. With the thumb and forefinger of the left hand, the measurement is made by first grasping the skinfold parallel to the long axis of the upper arm and $1 \mathrm{~cm}$ below the midpoint mark. After allowing the underlying muscle to slide free, the skinfold is gently compressed and with the caliper perpendicular to the length of the arm, the prongs are placed just above the fingers on both sides of the cross mark, making sure that the two folds of skin and underlying fat are evenly positioned between the prongs of the caliper. Once the pointer has stabilized, the measurement is recorded. In the body density study this method resulted in an intraobserver coefficient of variation for measurement error of 
4.4\%. In the larger sample of the Bogalusa Heart Study children, the intraobserver coefficient of variation was $7.2 \%$ while the interobserver coefficient was $7.8 \%$.

Several weight-height indices were derived for each child. In three of the indices, weight (W, in kilograms) was divided by a power function of height $\left(\mathbf{H}\right.$, in meters) as follows: $\mathbf{W} / \mathbf{H}, \mathbf{W} / \mathbf{H}^{2}$ (Quetelet or body mass Index), and $\mathrm{W} / \mathrm{H}^{3}$ (modification of the ponderal index). Relative weight was determined by dividing each child's weight by the median weight of children examined in the United States Health Examination Survey who were of the same age, sex, and height category $(17,18)$. Relative weight was not determined for 6 of the 214 children because they had heights outside the range of the Health Examination Survey tables.

\section{DENSITOMETRIC MEASUREMENT}

As had been described elsewhere $(12,13)$, each of the 214 children underwent a hydrostatic determination of body density which allows for the calculation of percentage of body fat using the formula of Siri [(495/density) - 450] (22). Three independent densitometric readings were made on each subject with the mean of the three readings included in the analysis. Based on a replicate examination within $3 \mathrm{hr}$ of 60 children, the SD of measurement error for his procedure was $1.35 \%$ body fat, with a coefficient of variation of $5.56 \%(13)$.

\section{STATISTICAL ANALYSIS}

Both Pearson product-moment correlation coefficients and multiple linear regression were used to determine the relationship among the measured and derived variables. All analyses were performed on untransformed data. Since skinfold distributions are skewed toward higher values, the analyses involving the triceps were performed twice with the measurement entered either in an untransformed or log-transformed state. The results were nearly equivalent. Consequently, for ease of subsequent usage, the triceps data remain untransformed.

\section{RESULTS}

The mean values for the volunteer sample of 214 children of height, weight, triceps skinfold thickness, and percentage of body fat derived from underwater weighing are shown by age and sex in Table 1. In general, the girls in this selected sample tended to both weigh more and have a thicker triceps skinfold than the boys. There were no consistent differences observed in height between the sexes. At every age, percentage of body fat was greater in girls than in boys.

The bivariate correlation coefficients between several obesity indices and percentage of body fat are shown by sex in Table 2 . Within this sample of 10 - to I4-year olds, the correlation of percentage of body fat was consistently greater with the triceps skinfold thickness than with any of the indices derived from measuring height and weight. Among the four weight-height indices, the highest correlation with percentage of body fat was displayed by either $\mathrm{W} / \mathrm{H}^{3}$ or relative weight with the coefficient being slightly lower for $\mathrm{W} / \mathrm{H}^{2}$ and considerably lower for $\mathrm{W} / \mathrm{H}$.

Although correlation coefficients provide an indication of the strength of the linear relationship between two variables, they do not enable us to predict the value of one variable based on the level of the other. For predictive purposes, we derived a series of linear regression equations with percentage of body fat as the dependent variable (the variable to be predicted) and combinations of height, weight, and triceps skinfold as the independent variables. Five sets of equations applicable to either boys or girls are shown in Table 3 . In the first set, the necessary measurements are weight, height, and triceps skinfold. The form of the equation is as follows: Body fat (\%) $=$ constant $+b_{1}$ (weight) $+b_{2}$ (height) $+b_{3}$ (triceps skinfold), where $b_{1}, b_{2}$, and $b_{3}$ are the regression coefficients shown in Table 3 for each sex under weight, height, and triceps skinfold, respectively. For example, assume we have a 12-year-old boy who weighs $43 \mathrm{~kg}$, is $152 \mathrm{~cm}$ tall, and has a triceps skinfold of $14 \mathrm{~mm}$. His percentage of body fat would be estimated, using the first equation in Table 3 , as $51.73+(0.28 \times$ $43)+(-0.35 \times 152)+(0.78 \times 14)=21.5 \%$ body fat. Within our sample population of 111 boys, the multiple $R^{2}$ statistic indicates that this formula explained $72 \%$ of the variation between boys in percentage of body fat. A multiple $R^{2}$ value of 1.00 would mean that knowledge of the independent variables would result in an exact prediction of percentage of body fat. By including in the equation the subcapsular skinfold as well as height, weight, and the triceps skinfold, our ability to predict percentage of body fat was increased very slightly with multiple $R^{2}$ of 0.74 for boys and 0.75 for girls. The inclusion of all six skinfolds (triceps, biceps, subscapular, suprailiac, subcostal, and calf as well as height and weight resulted in multiple $\mathrm{R}^{2}$ of 0.78 in boys and 0.79 in girls, only moderately greater than the multiple $R^{2} s$ based on height, weight, and the triceps skinfold.

Figure 1 shows the relationship in a scatter diagram between percentage of body fat derived from hydrostatic weighing with percentage of body fat calculated for each sex using the first set of

Table 2. Simple correlation coefficients between percentage of body fot and selected obesity indices in children, $10-14$ years old, by $\operatorname{sex}(n=214)$

\begin{tabular}{lcc}
\hline \multicolumn{1}{c}{ Obesity indices' } & $\begin{array}{c}\text { Boys } \\
(n=111)\end{array}$ & $\begin{array}{c}\text { Girls } \\
(n=103)\end{array}$ \\
\hline W/H & 0.43 & 0.62 \\
W/H & 0.60 & 0.71 \\
W/H & 0.73 & 0.75 \\
Relative weight ${ }^{2}$ & 0.72 & 0.77 \\
Triceps skinfold & 0.82 & 0.82 \\
\hline
\end{tabular}

' $\mathrm{W}(\mathrm{kg}), \mathrm{H}(\mathrm{cm})$, relative weight $=[$ weight $/$ median weight for height (Health Examination Survey, age and sex specific)] $([7,18)$.

${ }^{2}$ Unable to calculate relative weight for four boys and two girls. All entries statistically significant, $P<0,0001$.

Table 1. Mean and SD of anthropometric measurements and percentage of body fat derived by densitometry in children, 10-14 years old, by age and sex $(n=214)$

\begin{tabular}{|c|c|c|c|c|c|c|}
\hline Age $(y r)$ & Sex & $\begin{array}{l}\text { No. of chil- } \\
\text { dren }\end{array}$ & Weight (kg) & Height (cm) & $\begin{array}{c}\text { Triceps } \\
\text { skinfold } \\
\text { (mm) }\end{array}$ & $\begin{array}{l}\text { Body fat } \\
(\%)^{\prime}\end{array}$ \\
\hline 10 & Boys & 13 & $36.3 \pm 8.5$ & $143.0 \pm 7.4$ & $14.6 \pm 7.4$ & $23.5 \pm 7.4$ \\
\hline \multirow[t]{2}{*}{11} & Boys & 24 & $38.8 \pm 9.8$ & $145.2 \pm 6.4$ & $13.6 \pm 6.8$ & $21.9 \pm 6.9$ \\
\hline & Girls & 24 & $42.5 \pm 10.5$ & $148.6 \pm 6.0$ & $17.6 \pm 8.8$ & $29.1 \pm 8.8$ \\
\hline 12 & Boys & 29 & $44.9 \pm 9.5$ & $150.9 \pm 6.6$ & $14.8 \pm 6.9$ & $22.6 \pm 8.6$ \\
\hline 13 & Girls & 28 & $49.8 \pm 10.3$ & $160.1 \pm 9.0$ & $16.8 \pm 6.3$ & $25.8 \pm 7.7$ \\
\hline \multirow[t]{2}{*}{14} & Boys & 20 & $51.7 \pm 8.4$ & $162.7 \pm 6.3$ & $11.4 \pm 5.4$ & $17.4 \pm 6.7$ \\
\hline & Girls & 13 & $56.4 \pm 10.8$ & $159.4 \pm 6.6$ & $21.1 \pm 6.2$ & $28.8 \pm 8.3$ \\
\hline
\end{tabular}

\footnotetext{
' Body fat $(\%)=[(49 S /$ density $)-450]$; Siri $(22)$.
} 